\title{
Compression Aid Excipient
}

National Cancer Institute

\section{Source}

National Cancer Institute. Compression Aid Excipient. NCI Thesaurus. Code C42655.

Therapeutically inactive substance that helps to make pills hold their shape upon

compression and improve compressibility properties in general. 